\title{
Optimal Management of Brine from Seawater Desalination Plants in Gaza Strip: Deir AL Balah STLV Plant as Case Study
}

\author{
Yunes Mogheir ${ }^{1}$, Nasser Al Bohissi ${ }^{2}$ \\ ${ }^{1}$ Environmental Engineering Department, Engineering Faculty, Islamic University of Gaza, Gaza, Palestine \\ ${ }^{2}$ Civil Engineering Department, Engineering Faculty, Islamic University of Gaza, Gaza, Palestine \\ Email: ymogheir@iugaza.edu.ps
}

Received 14 April 2015; accepted 27 June 2015; published 30 June 2015

Copyright (C) 2015 by authors and Scientific Research Publishing Inc.

This work is licensed under the Creative Commons Attribution International License (CC BY).

http://creativecommons.org/licenses/by/4.0/

(c) $\underset{\mathrm{EY}}{\mathrm{B}}$ Open Access

\begin{abstract}
Brine salty water that is produced from Reverse Osmosis desalination plants usually has very large quantity and contains much higher salts ratio than that found in the sea. The disposal of such brine water has risks on environment. The objective of the research is to investigate the best brine disposal option in Gaza Strip. Five options for the disposal of brine were studied: 1) disposal of brine to the sea; 2) discharge of brine to wastewater plant; 3) deep well injection; 4) evaporation pond and 5) land irrigation. The new desalination plant Short-Term Low Volume (STLV) of a capacity of $6000 \mathrm{~m}^{3} / \mathrm{d}$ was used as a case study. Initially, the cost for each option was calculated separately, where it was found that the least cost is to pump the brine to the sea without affecting the seawater and marine life. To support this decision, two methods were used to reach the optimal option for the disposal of brine: Multi-Criteria Analysis (MCA) and Analytic Hierarchy Process (AHP). In MCA the measurement includes: economic, environmental, technical, political and social aspects, depending on a group of academics and experts in that field to fill in the questionnaire, which is a part of the analysis. As a result of that, the highest percentage among other options goes to pump the brine directly to the sea. On the other hand, the second method, which is Analytic Hierarchy Process (AHP), used the method of matrices among the different options and linked it with the standards that have been selected in the first method (MCDA). AHP method indicated also the best disposal of brine by pumping the brine to the sea.
\end{abstract}

\section{Keywords}

Brine, Reverse Osmosis, Multi-Criteria, Analytic Hierarchy Process 


\section{Introduction}

Water is essential to sustain life, and should be adequate, safe and accessible to all. The unsafe drinking-water can result in high risk to health. Every effort should be made to achieve a drinking-water quality as safe as possible.

Gaza Strip suffering from the huge increasing in population which depends mainly on a ground water. During the last years, water quality has deteriorated and became unsuitable for human consumption in most parts of the strip.

To face this problem, the citizens and the authority in Gaza Strip use many options; the major of these options is water desalination where the reverse osmosis (RO) technology is applied in all desalination plants in Gaza Strip. Since then, many large and small scale desalination plants were built and operated to provide potable water for the population of Gaza Strip who has limited water supplies and depends mostly on groundwater, the salinity levels of which are seriously high (TDS: $2200 \mathrm{mg} / \mathrm{l}$ and above) [1]. In the past twenty years, sixbrackish water desalination plants were built and one seawater desalination plant as well. The desalinated water produced from these plants represents nearly $4 \%$ of the total water consumption by the population. More than $90 \%$ of this population depends on the desalinated water for drinking purposes [2]. Practically, there are seven public desalination plants located all over the Gaza Strip operated by the Coastal Municipal Water Utilities (CMWU), the operating water body in Gaza Strip [3] [4]. These plants provide drinking water for the population in the middle and southern parts of the Gaza Strip. All of them are brackish water desalination plants except for one seawater RO plant located in the middle area of Gaza Strip. Three plants have been built 2 or 3 years ago while the rest have been operating for more than 12 years. These public plants have shown better performance and more significance when compared with small private plants. In addition, these plants are linked directly to the municipal water networks while private plants have distribution tanks and collecting points where people have to collect the water on their own [5]. And new plant will be located in Deir Al Balah Governorate, at the border with Khan younis governorate, and will serve Rafah and Khan younis governorates. 80 dunums have been allocated to this purpose from the Palestinian Land Authority (PLA). The land is being waived to PWA for the benefits of the planned regional desalination plant and will be transferred to CMWU for operation purpose [6]. Desalination plants generate discharge that contains the plant's source water treatment byproducts, including concentrate, spent pretreatment filter backwash water, and membrane cleaning solutions. Concentrate is the desalination process byproduct of the largest volume and the greatest management challenges [7]. Despite the fact that many researchers have recently showed interest in studying the desalination practice in Gaza Strip, only few studies in the literature could be found [4] [8]. Recently Mogheir assessed the desalination practice in Gaza Strip [9]. According to his study, improper disposal of the desalination plants' brine effluent poses a serious threat to the environment in Gaza Strip. This work extends the focus on assessing the large scale Brackish Water Desalination Plants (BWDPs) in Gaza in terms of operational conditions and quality of desalinated water produced to indicate and recommend the possible improvements required in the near future. In addition, an evaluation is made for all plants to classify the weakest and strongest performing plants to assist in prioritizing the application of improvements [4] [9].

\section{Methods}

\subsection{Cost Estimation}

The five most commonly used concentrate management alternatives that considered in this research are: 1) surface water discharge; 2) sewer disposal; 3) deep-well injection; 4) evaporation pond; and 5) land application. Cost analysis of each option was carried out where the best option was selected. The cost analyses considered mainly the capital and the expected operation and maintenance costs.

\subsection{Multi-Criteria Analysis (MCA)}

MCA is both an approach and a set of techniques, with the goal of providing an overall ordering of options, from the most preferred to the least preferred option. The options may differ in the extent to which they achieve several objectives, and no one option will be obviously best in achieving all objectives. In addition, some conflict or trade-off is usually evident amongst the objectives, options that are more beneficial are also usually more 
costly, for example. Costs and benefits typically conflict, but so can short-term benefits compared to long-term ones, and risks may be greater for the otherwise more beneficial options. MCA is a way of looking at complex problems that are characterized by any mixture of monetary and non-monetary objectives, of breaking the problem into more manageable pieces to allow data and judgments to be brought to bear on the pieces, and then of reassembling the pieces to present a coherent overall picture to decision makers. The purpose is to serve as an aid to thinking and decision making [10]. The steps for MCA in this research are:

1) Establish aims of the MCA, and identify decision makers and other key players. The aim of the MCA in this research to get the best option for brine disposal. Academic experts and experts in the subject of research are invited to participate in MCA.

2) Identify the options to be appraised where choose four options of brine disposal were selected as:

- Pump brine to sea water.

- Deep well injection.

- Evaporation pond.

- Irrigation.

3) Four criteria were used in this research: economic which took 30\%, Environmental took 35\%, technical took $20 \%$, social and political took $15 \%$. The criteria and its load were suggested by academics and experts persons.

4) Each option were rated and assessed against the four criteria. Then assess the value associated with the consequences of each option for each criterion, also rating put by academics and experts persons. The scale for these rating is from 1 to 5 .

5) Assign weights (Weighting) for each of the criterion to reflect their relative importance to the decision. Weights put by academics and experts persons, the scale in weighting from is from 1 to 3 .

6) Combine the weights and rating for each option to derive an overall value and then examine the results.

\subsection{Analytical Hierarchy Process (AHP)}

The Analytical Hierarchy Process (AHP) is a decision-aiding method developed by Saaty. It aims at quantifying relative priorities for a given set of alter-natives on a ratio scale, based on the judgment of the decision-maker, and stresses the importance of the intuitive judgments of a decision-maker as well as the consistency of the comparison of alternatives in the decision-making process [11]. Since a decision-maker bases judgments on knowledge and experience, then makes decisions accordingly, the AHP approach agrees well with the behavior of a decision-maker. The strength of this approach is that it organizes tangible and intangible factors in a systematic way, and provides a structured yet relatively simple solution to the decision-making problems [12].

In addition, by breaking a problem down in a logical fashion from the large, descending in gradual steps, to the smaller and smaller, one is able to connect, through simple paired comparison judgments, the small to the large.

The following steps were followed for applying AHP:

1) Define the problem and determine its goal.

2) Structure the hierarchy from the top (the objectives from a decision-makers viewpoint) through the intermediate levels (criteria on which subsequent levels depend) to the lowest level which usually contains the list of alternatives.

3) Construct a set of pair wise comparison matrices (size $n \times n$ ) for each of the lower levels with one matrix for each element in the level immediately above by using the relative scale measurement shown in Table 1 . The pair-wise comparisons are done in terms of which element dominates the other.

4) $n(n-1)$ judgments required to develop the set of matrices in step 3. Reciprocals are automatically assigned in each pair wise comparison.

5) Hierarchical synthesis is now used to weight the eigenvectors by the weights of the criteria and the sum is taken over all weighted eigenvector entries corresponding to those in the next lower level of the hierarchy.

6) Having made all the pair-wise comparisons, the consistency is determined by using the Eigen value, $\lambda_{\max }$, to calculate the consistency index, $\mathrm{CI}$ as fol-lows:

$$
\mathrm{CI}=\left(\lambda_{\max }-n\right) /(n-1)
$$

where:

$n$ is the matrix size. Judgment consistency can be checked by taking the consistency ratio (CR) of CI with the 
Table 1. Pair-wise comparison scale for AHP preferences [11].

\begin{tabular}{ccc}
\hline Numerical rating & Verbal judgments of preferences \\
\hline $\mathbf{9}$ & Extremely preferred \\
$\mathbf{8}$ & Very strongly to extremely \\
$\mathbf{6}$ & Very strongly preferred \\
$\mathbf{5}$ & Strongly to very strongly \\
$\mathbf{4}$ & Strongly preferred \\
$\mathbf{3}$ & Moderately to strongly \\
$\mathbf{2}$ & Moderately preferred \\
$\mathbf{1}$ & Equally to moderately \\
\hline
\end{tabular}

appropriate value (RI) in Table 2.

$$
\mathrm{CR}=\mathrm{CI} / \mathrm{RI}
$$

The CR is acceptable, if it does not exceed 0.10. If it is more, the judgment matrix is inconsistent. To obtain a consistent matrix, judgments should be reviewed and improved.

7) Steps 3 and 6 are performed for all levels in the hierarchy. Then, the following can be done manually or automatically by the AHP software, Expert Choice:

- synthesizing the pair-wise comparison matrix.

- calculating the priority vector for a criterion such as experience.

- calculating the consistency ratio.

- calculating $\lambda_{\max }$.

- calculating the consistency index, CI.

- $\quad$ selecting appropriate value of the random consistency ratio from Table 2.

- checking the consistency of the pair wise comparison matrix to check whether the decision makers comparisons were consistent or not.

\section{Results and Discussion}

\subsection{Cost Analysis of Each Option}

The construction cost, operation and maintenance cost for each option were obtained and presented in Table 3.

\subsection{Generic Matrix Approach (GMA)}

The results of each one of the eight experts, academic and professionals, are obtained for four alternatives: surface discharge, deep well injection, evaporation pond and finally the irrigation. Table 4 shows the average weights and rates for the eight experts for the same four alternatives. In such that type of analysis, the options were reduced to four rather than five options, where the second option was excluded (Discharge brine to wastewater plant) because the amount of brine was very large and the plant couldn't accommodate that amount.

Figure 1 indicates the results of GMA and the options can be ordered as follows:

1) Pump to seawater (P.S) that obtained $70.8 \%$.

2) Deep well injection (D.W) that obtained $47 \%$.

3) Evaporation pond (E.P) that obtained 55.7\%.

4) Irrigation (IR) that obtained $47.6 \%$.

It can be clearly seen that the best option is brine disposal to the sea which got $70.8 \%$

\subsection{Analytical Hierarchy Process (AHP) Results}

The results of the calculations for these AHP was explained for illustration purposes. Synthesizing the pair-wise comparison matrix was performed by dividing each element. 
Table 2. Average random consistency (RI) [11].

\begin{tabular}{cccccccccccc}
\hline Size of matrix & $\mathbf{1}$ & $\mathbf{2}$ & $\mathbf{3}$ & $\mathbf{4}$ & $\mathbf{5}$ & $\mathbf{6}$ & $\mathbf{7}$ & $\mathbf{8}$ & $\mathbf{9}$ & $\mathbf{1 0}$ \\
\hline Random consistency & 0 & 0 & 0.58 & 0.9 & 1.12 & 1.24 & 1.32 & 1.41 & 1.45 & 1.49 \\
\hline
\end{tabular}

Table 3. The result for all options.

\begin{tabular}{cccc} 
& Options & Cost \$ \\
\hline $\mathbf{1}$ & Pump to sea water & $108,108 \$$ \\
$\mathbf{2}$ & Pump to wastewater plant & $1,270,681$ \\
$\mathbf{3}$ & Deep Well injection & $333,476 \$$. \\
$\mathbf{4}$ & Evaporation pond & $62,845,229 \$$ \\
$\mathbf{5}$ & Irrigation & $5,000,000 \$$ \\
\hline
\end{tabular}

Table 4. The average weigh \& rate for GMA method.

\begin{tabular}{|c|c|c|c|c|c|c|c|c|c|}
\hline \multicolumn{2}{|l|}{ Score } & \multicolumn{2}{|c|}{ Alternative 1} & \multirow{2}{*}{\multicolumn{2}{|c|}{$\begin{array}{c}\text { Alternative } 2 \\
\begin{array}{c}\text { Deep well } \\
\text { injection }\end{array}\end{array}$}} & \multirow{2}{*}{\multicolumn{2}{|c|}{$\begin{array}{c}\text { Alternative } 3 \\
\text { Evaporation } \\
\text { ponds }\end{array}$}} & \multirow{2}{*}{\multicolumn{2}{|c|}{$\begin{array}{c}\text { Alternative } 4 \\
\text { Irrigation }\end{array}$}} \\
\hline \multirow[t]{2}{*}{ Criteria } & \multirow{2}{*}{$\begin{array}{l}\text { Weight } \\
1,2,3\end{array}$} & \multicolumn{2}{|c|}{ Pump to seawater } & & & & & & \\
\hline & & Rating & PTS & Rating & PTS & Rating & PTS & Rating & PTS \\
\hline \multicolumn{10}{|l|}{ Economic (30\%) } \\
\hline Construction cost & 2.4 & 4.4 & 10.6 & 2.1 & 5.0 & 2.3 & 5.5 & 2.1 & 5.0 \\
\hline $\mathrm{O} \& \mathrm{M}$ & 2.3 & 3.8 & 8.7 & 2.2 & 5.1 & 3.3 & 7.6 & 1.8 & 4.1 \\
\hline Subtotal & 4.7 & & 19.3 & & 10.1 & & 13.1 & & 9.2 \\
\hline Maximum points estimated \% & 23.5 & & & & & & & & \\
\hline Percentages \% & & & 24.6 & & 12.9 & & 16.7 & & 11.7 \\
\hline \multicolumn{10}{|l|}{ Environmental (35\%) } \\
\hline Pollution impact & 2.9 & 2.6 & 7.5 & 2.9 & 8.4 & 3.2 & 9.3 & 2.7 & 7.8 \\
\hline Sustainability & 2.1 & 3.6 & 7.6 & 1.6 & 3.4 & 3.0 & 6.3 & 1.8 & 3.8 \\
\hline Subtotal & 5.0 & & 15.1 & & 11.8 & & 15.6 & & 11.6 \\
\hline Maximum points estimated & 25.0 & & & & & & & & \\
\hline Percentages \% & & & 21.1 & & 16.5 & & 21.8 & & 16.3 \\
\hline \multicolumn{10}{|l|}{ Technical (20\%) } \\
\hline Time of construction & 1.5 & 4.7 & 7.1 & 1.7 & 2.6 & 2.8 & 4.2 & 1.9 & 2.9 \\
\hline Future expansion & 2.3 & 4.3 & 9.9 & 2.1 & 4.8 & 2.0 & 4.6 & 2.3 & 5.3 \\
\hline Easy of construction & 2.0 & 4.5 & 9.0 & 2.2 & 4.4 & 3.1 & 6.2 & 3.2 & 6.4 \\
\hline Easy of O\&M & 2.5 & 4.8 & 12.0 & 2.1 & 5.3 & 2.9 & 7.3 & 2.1 & 5.3 \\
\hline Risk & 2.8 & 2.9 & 8.1 & 2.3 & 6.4 & 2.0 & 5.6 & 2.8 & 7.8 \\
\hline Subtotal & 11.1 & & 46.1 & & 23.5 & & 27.9 & & 27.6 \\
\hline Maximum points estimated & 55.5 & & & & & & & & \\
\hline Percentages \% & & & 16.6 & & 8.5 & & 10.0 & & 10.0 \\
\hline \multicolumn{10}{|l|}{ Political social (15\%) } \\
\hline Political constraints & 1.6 & 2.7 & 4.3 & 3.4 & 5.4 & 2.8 & 4.5 & 3.5 & 5.6 \\
\hline Social impact & 2.2 & 2.8 & 6.2 & 3.5 & 7.7 & 1.9 & 4.2 & 3.4 & 7.5 \\
\hline Water price acceptance & 1.8 & 3.4 & 6.1 & 2.2 & 4.0 & 2.1 & 3.8 & 2.6 & 4.7 \\
\hline Legal requirements & 2.2 & 2.4 & 5.3 & 3.1 & 6.8 & 2.8 & 6.2 & 3.3 & 7.3 \\
\hline Subtotal & 7.8 & & 21.9 & & 23.9 & & 18.6 & & 25.0 \\
\hline Maximum points estimated & 39.0 & & & & & & & & \\
\hline Percentages \% & & & 8.4 & & 9.2 & & 7.2 & & 9.6 \\
\hline Total \% & & & $70.8 \%$ & & $47.0 \%$ & & $55.7 \%$ & & $47.6 \%$ \\
\hline
\end{tabular}




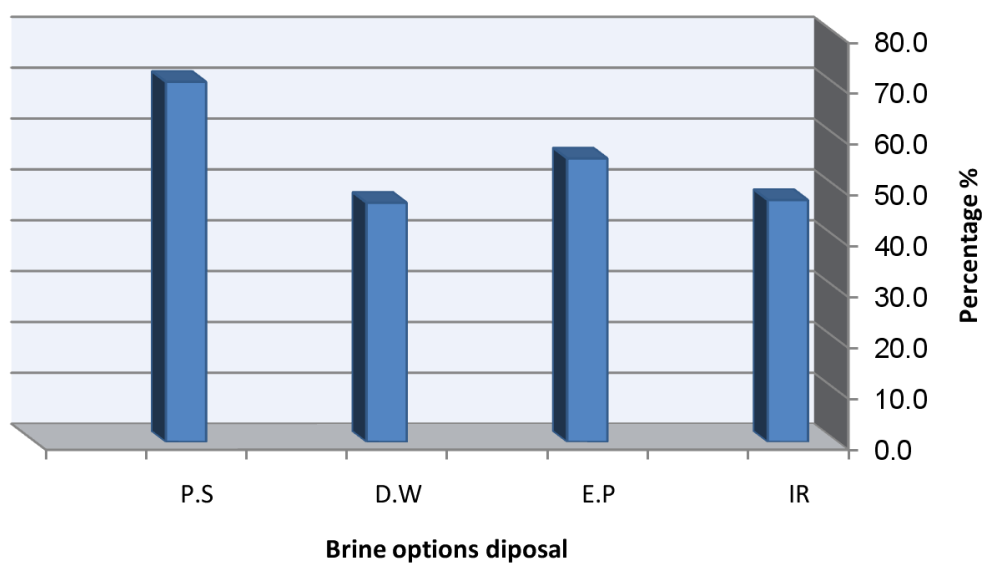

Figure 1. The overall weight for the average GMA method.

Table 5 indicates the weight for every option with regard to criteria of economic cost, where these weights have been set by experts. For example, A take regard to B in economic cost 3 while B regard to A take 1/3.

This process will be repeated in Tables 6-10 but with different criteria. Of the matrix by its column total. For example, the value 0.08 in Table 6 is obtained by dividing 1 from Table 5 by 12.5, which the sum of column items in Table $5(1+3+2+6+1 / 2)=12.5$.

The priority vector in Table 6 can be obtained by finding the row averages. For example, the priority of option A with respect to the criterion "experience" in Table 6 is calculated by dividing the sum of the rows $(0.08$, $0.08,0.07,0.08,0.12$ ) by the number of options (columns), i.e., 5 , in order to obtain the value 0.09 . The priority vector for experience, indicated in Table 6.

Now, estimating the consistency ratio is as follows:

$$
0.09\left[\begin{array}{c}
1 \\
3 \\
2 \\
6 \\
1 / 2
\end{array}\right]+0.25\left[\begin{array}{c}
1 / 3 \\
1 \\
1 / 2 \\
2 \\
1 / 4
\end{array}\right]+0.0 .15\left[\begin{array}{c}
1 / 2 \\
2 \\
1 \\
3 \\
1 / 3
\end{array}\right]+0.46\left[\begin{array}{c}
1 / 6 \\
1 / 2 \\
1 / 3 \\
1 \\
1 / 7
\end{array}\right]+0.06\left[\begin{array}{c}
2 \\
4 \\
3 \\
7 \\
1
\end{array}\right]
$$

where $(0.09,0.25,0.15,0.46$ and 0.06$)$ from Table 6 and these matrices from Table 5. Dividing all the elements of the weighted sum matrices by their respective priority vector element, we obtain:

$$
\frac{0.43}{0.09}=5.02, \frac{1.26}{0.25}=5.06, \frac{0.77}{0.15}=5.04, \frac{2.31}{0.46}=5.06, \frac{0.28}{0.06}=5.02
$$

We then compute the average of these values to obtain:

$$
\lambda_{\text {max }}=\frac{5.02+5.06+5.04+5.06+5.02}{5}=5.04
$$

Now, we find the consistency index, CI, as follows:

$$
\mathrm{CI}=\frac{\left(\lambda_{\max }-n\right)}{n-1}=\frac{5.04-5}{4}=0.01
$$

Selecting appropriate value of random consistency ratio, RI, for a matrix size of five using Table 2, we find that $\mathrm{RI}=1.12$. Then the consistency ratio is calculated (CR) as follows:

$$
\mathrm{CR}=\frac{\mathrm{CI}}{\mathrm{RI}}=\frac{0.01}{1.12}=0.01<0.1 \quad \mathrm{ok}
$$

As the value of CR is less than 0.1 , the judgments are acceptable. Similarly, the pair-wise comparison matrices and priority vectors for the remaining criteria can be found in Tables 7-15, respectively. Table 7 and Table 8 
Table 5. Pair-wise comparison matrix for economic.

\begin{tabular}{cccccc}
\hline E.C. & A & B & C & D & E \\
\hline A & 1 & $1 / 3$ & $1 / 2$ & $1 / 6$ & $1 / 2$ \\
B & 3 & 1 & 2 & $1 / 3$ & 4 \\
C & 2 & $1 / 2$ & 1 & 1 & 3 \\
D & 6 & 2 & 3 & $1 / 7$ & 7 \\
E & $1 / 2$ & $1 / 4$ & $1 / 3$ & 2.14 & 1 \\
Sum & 12.50 & 4.08 & 6.83 & & 17.00 \\
\hline
\end{tabular}

Table 6. Synthesized matrix for experience.

\begin{tabular}{ccccccc}
\hline E.C. & A & B & C & D & E & Priority Vector \\
\hline A & 0.08 & 0.08 & 0.07 & 0.08 & 0.12 & 0.09 \\
B & 0.24 & 0.24 & 0.29 & 0.23 & 0.24 & 0.25 \\
C & 0.16 & 0.12 & 0.15 & 0.16 & 0.18 & 0.15 \\
D & 0.48 & 0.49 & 0.44 & 0.47 & 0.41 & 0.46 \\
E & 0.04 & 0.06 & 0.05 & 0.07 & 0.06 & 0.06 \\
& & & & & Sum & 1.00 \\
\hline
\end{tabular}

Table 7. Pair-wise comparison matrix for environmental criteria.

\begin{tabular}{cccccc}
\hline E.N & A & B & C & D & E \\
\hline A & 1 & 6 & 3 & 2 & 7 \\
B & $1 / 6$ & 1 & $1 / 4$ & $1 / 2$ & 3 \\
C & $1 / 3$ & 4 & 1 & $1 / 3$ & 5 \\
D & $1 / 2$ & 2 & 3 & 1 & 7 \\
E & $1 / 7$ & $1 / 3$ & $1 / 5$ & 3.98 & 1 \\
& 2.14 & 13.33 & 7.45 & & 23.00 \\
\hline
\end{tabular}

Table 8. Priority vector comparison for environmental criteria.

\begin{tabular}{ccccccc}
\hline E.N & A & B & C & D & E & Priority Vector \\
\hline A & 0.47 & 0.45 & 0.40 & 0.50 & 0.30 & 0.43 \\
B & 0.08 & 0.08 & 0.03 & 0.13 & 0.13 & 0.09 \\
C & 0.16 & 0.30 & 0.13 & 0.08 & 0.22 & 0.18 \\
D & 0.23 & 0.15 & 0.40 & 0.25 & 0.30 & 0.27 \\
E & 0.07 & 0.03 & 0.03 & 0.04 & 0.04 & 0.04 \\
\end{tabular}

Table 9. Pair-wise comparison matrix for technical criteria.

\begin{tabular}{cccccc}
\hline T.E & A & B & C & D & E \\
\hline A & 1 & 7 & $1 / 3$ & 2 & 8 \\
B & $1 / 7$ & 1 & $1 / 5$ & $1 / 4$ & 4 \\
C & 3 & 5 & 1 & 4 & 9 \\
D & $1 / 2$ & 4 & $1 / 4$ & 1 & 6 \\
E & $1 / 8$ & $1 / 4$ & $1 / 9$ & $1 / 6$ & 1 \\
& 4.77 & 17.25 & 1.89 & 7.42 & 28.00 \\
\hline
\end{tabular}


Table 10. Priority vector matrix for technical criteria.

\begin{tabular}{cccccccc}
\hline T.E & A & B & C & D & E & Priority Vector \\
\hline A & 0.21 & 0.41 & 0.18 & 0.27 & 0.29 & 0.27 \\
B & 0.03 & 0.06 & 0.11 & 0.03 & 0.14 & 0.07 \\
C & 0.63 & 0.29 & 0.53 & 0.54 & 0.32 & 0.46 \\
D & 0.10 & 0.23 & 0.13 & 0.13 & 0.21 & 0.16 \\
E & 0.03 & 0.01 & 0.06 & 0.02 & 0.04 & 0.03 \\
\end{tabular}

Table 11. Pair-wise comparison matrix for political criteria.

\begin{tabular}{cccccc}
\hline P.O & A & B & C & D & E \\
\hline A & 1 & $1 / 2$ & $1 / 4$ & 2 & 5 \\
B & 2 & 1 & $1 / 3$ & 5 & 7 \\
C & 4 & 3 & 1 & 4 & 6 \\
D & $1 / 2$ & $1 / 5$ & $1 / 4$ & 1 & 2 \\
E & $1 / 5$ & $1 / 7$ & $1 / 6$ & $1 / 2$ & 1 \\
& 7.70 & 4.84 & 2.00 & 12.50 & 21.00 \\
\hline
\end{tabular}

Table 12. Priority vector matrix for political criteria.

\begin{tabular}{cccccccc}
\hline P.O & A & B & C & D & E & Priority Vector \\
\hline A & 0.13 & 0.10 & 0.13 & 0.16 & 0.24 & 0.15 \\
B & 0.26 & 0.21 & 0.17 & 0.40 & 0.33 & 0.27 \\
C & 0.52 & 0.62 & 0.50 & 0.32 & 0.29 & 0.45 \\
D & 0.06 & 0.04 & 0.13 & 0.08 & 0.10 & 0.08 \\
E & 0.03 & 0.03 & 0.08 & 0.04 & 0.05 & 0.05 \\
\end{tabular}

Table 13. Pair-wise comparison matrix for social criteria.

\begin{tabular}{cccccc}
\hline S.O & A & B & C & D & E \\
\hline A & 1 & $1 / 6$ & $1 / 8$ & 2 & 3 \\
B & 6 & 1 & $1 / 4$ & 5 & 7 \\
C & 8 & 4 & 1 & 9 & 9 \\
D & $1 / 2$ & $1 / 5$ & $1 / 9$ & 1 & 2 \\
E & $1 / 3$ & $1 / 7$ & $1 / 9$ & $1 / 2$ & $1 / 2$ \\
\end{tabular}

presented the results of environmental criteria were: $\lambda_{\max }=5.32, \mathrm{CI}=0.08, \mathrm{RI}=1.12$. It can be noticed that CR is less than 0.1 which can be accepted.

Table 9 and Table 10 presented the results of technical criteria were: $\lambda_{\max }=5.24, \mathrm{CI}=0.06$, RI $=1.12$, and CR is 0.05 which is less than 0.1 and it can be accepted. Table 11 and Table 12 presented the results of political criteria were: $\lambda_{\max }=5.24$, CI $=0.06$, RI $=1.12$, and CR is 0.05 which is less than 0.1 and it can be accepted.

Table 13 and Table 14 presented the results of political criteria were: $\lambda_{\max }=5.28, \mathrm{CI}=0.07, \mathrm{RI}=1.12$, and CR is 0.06 which is less than 0.1 and it can be accepted. 
In addition to the pair-wise comparison for the decision alternatives, we also use the same pair-wise comparison procedure to set priorities for all five criteria in terms of importance of each in contributing to the overall goal. Table 15 and Table 16 show the pair-wise comparison matrix and priority vector for the five criteria. The results are: $\lambda_{\max }$ is $5.20, \mathrm{CI}$ is 05 , RI is 0.12 and CR is 0.04 which is less than 0.1 and its also can be accepted.

Manually combine the criterion priorities and the priorities of each decision alternative relative to each criterion in order to develop an overall priority ranking of the decision alternative which is termed as the priority matrix Table 17. The overall priority of option A is obtained as follows:

Table 14. Priority vector matrix for social criteria.

\begin{tabular}{ccccccc}
\hline S.O & A & B & C & D & E & Priority Vector \\
\hline A & 0.06 & 0.03 & 0.08 & 0.11 & 0.14 & 0.08 \\
B & 0.38 & 0.18 & 0.16 & 0.29 & 0.32 & 0.26 \\
C & 0.51 & 0.73 & 0.63 & 0.51 & 0.41 & 0.56 \\
D & 0.03 & 0.04 & 0.07 & 0.06 & 0.09 & 0.06 \\
E & 0.02 & 0.03 & 0.07 & 0.03 & 0.05 & 0.04 \\
\hline
\end{tabular}

Table 15. Pair-wise comparison matrix for the five criteria.

\begin{tabular}{cccccc}
\hline & EC & EN & TE & PO & SO \\
\hline EC & 1 & 2 & 3 & 6 & 6 \\
EN & $1 / 2$ & 1 & 3 & 6 & 6 \\
TE & $1 / 3$ & $1 / 3$ & 1 & 4 & 4 \\
PO & $1 / 6$ & $1 / 6$ & $1 / 4$ & 1 & 2 \\
SO & $1 / 6$ & $1 / 6$ & $1 / 4$ & $1 / 2$ & 1 \\
& 2.17 & 3.50 & 7.25 & 16.50 & 19.00 \\
\hline
\end{tabular}

Table 16. Priority vector matrix for the five criteria.

\begin{tabular}{ccccccc}
\hline & EC & EN & TE & PO & SO & Priority Vector \\
\hline EC & 0.46 & 0.57 & 0.41 & 0.36 & 0.32 & 0.53 \\
EN & 0.23 & 0.29 & 0.41 & 0.36 & 0.32 & 0.40 \\
TE & 0.15 & 0.10 & 0.14 & 0.24 & 0.21 & 0.21 \\
PO & 0.08 & 0.05 & 0.03 & 0.06 & 0.11 & 0.08 \\
SO & 0.08 & 0.05 & 0.03 & 0.03 & 0.05 & 0.06 \\
\end{tabular}

Table 17. Priority matrix for options prequalification.

\begin{tabular}{ccccccc}
\hline & EC & EN & TE & PO & SO & Overall priority \\
\hline$\lambda_{\text {max }}$ & $\mathbf{0 . 5 3}$ & $\mathbf{0 . 4 0}$ & $\mathbf{0 . 2 1}$ & $\mathbf{0 . 0 8}$ & $\mathbf{0 . 0 6}$ & 0.29 \\
$\mathbf{A}$ & 0.09 & 0.43 & 0.27 & 0.15 & 0.08 & 0.22 \\
$\mathbf{B}$ & 0.25 & 0.09 & 0.07 & 0.27 & 0.26 & 0.32 \\
$\mathbf{C}$ & 0.15 & 0.18 & 0.46 & 0.45 & 0.56 & 0.40 \\
$\mathbf{D}$ & 0.46 & 0.27 & 0.16 & 0.08 & 0.06 & 0.06 \\
$\mathbf{E}$ & 0.06 & 0.04 & 0.03 & 0.05 & 0.04 & \\
\hline
\end{tabular}




$$
0.53(0.09)+0.4(0.43)+0.21(0.27)+0.08(0.15)+0.06(0.08)=0.29
$$

After that the options are ranked according to their overall priorities values as follows: D, C, A, B, and E, indicating that $\mathrm{D}$ is the best option.

\section{Conclusions and Recommendations}

It can be concluded that the best option for brine disposal of STLV project is pumping the brine to the sea. This was based on cost, applicability, MCDA and AHP. The conclusion was based also based on economic, environmental impact, technical, political and social criteria.

It is recommended that chemical and physical analyses of the disposed brine from seawater desalination plants should be carried out to assess and evaluate the significance effect on the marine life in separate studies. It also recommended that investigations should be done of subsurface layers especially layers beneath Saqiye in order to apply the deep well injection option and to ensure that there are no inverse effects on the ground water aquifer. Finally, mixing of brine water and treated wastewater and dispose the mixture into the sea, will reduce the high effect of both effluents.

\section{References}

[1] Abuhabib, A., Mohammad, A., Hilal, N., Rahman, R.A. and Shafie, A.H. (2012) Nanofiltration Membrane Modification by UV Grafting for Salt Rejection and Fouling Resistance Improvement for Brackish Water Desalination. Desalination, 295, 16-25. http://dx.doi.org/10.1016/j.desal.2012.03.020

[2] Al-Agha, M.R. and Mortaja, R.S. (2005) Desalination in the Gaza Strip: Drinking Water Supply and Environmental Impact. Desalination, 173, 157-171. http://dx.doi.org/10.1016/j.desal.2004.06.212

[3] CMWU (2009) Second Quarter Report for Disinfection \& Bi Annual Report of Water Quality in Gaza Strip in Coastal Municipalities Water Utility.

[4] Mogheir, Y., Foul, A., Abuhabib, A. and Mohammad, A. (2013). Assessment of Large Scale Brackish Water Desalination Plants in the Gaza Strip. Desalination, 314.

[5] El Sheikh, R., Ahmed, M. and Hamdan, S. (2003) Strategy of Water Desalination in the Gaza Strip. Desalination, 156, 39-42. http://dx.doi.org/10.1016/S0011-9164(03)00322-9

[6] CMWU (2013) Environmental and Social Impact Assessment (ESIA) For Short-Term Low Volume (STLV) Sea Water Desalination Plant for Southern Governorates of Gaza Strip.

[7] Mickley, M.C. (2009) Treatment of Concentrate. US Department of the Interior, Bureau of Reclamation, Technical Service Center, Water Treatment and Research Group, Denver, Colorado.

[8] Al-Khatib, I.A. and Arafat, H.A. (2009) Chemical and Microbiological Quality of Desalinated Water, Groundwater and Rain-Fed Cisterns in the Gaza Strip, Palestine. Desalination, 249, 1165-1170. http://dx.doi.org/10.1016/j.desal.2009.01.038

[9] Mogheir, Y., Foul, A.A., Abuhabib, A.A. and Mohammad, A.W. (2013) Large-Scale Brackish Water Desalination Plants in Gaza Strip: Assessments and Improvements. Journal of Water Reuse and Desalination. IWA Publication, Vol. 3, 315.

[10] Belton, V. and Stewart, T. (2002). Multiple Criteria Decision Analysis: An Integrated Approach. Springer Science \& Business Media, Berlin. http://dx.doi.org/10.1007/978-1-4615-1495-4

[11] Saaty, T.L. (1980) The Analytic Hierarchy Process. McGraw-Hill, New York.

[12] Voutchkov, N. (2012) Desalination Engineering: Planning and Design. McGraw Hill Professional, New York. 